\title{
Prognostic roles of mRNA expression of notch receptors in non- small cell lung cancer
}

\author{
Jianwen Xiong ${ }^{1, *}$, Xiaoqiang Zhang ${ }^{1, *}$, Xianglai Chen $^{1}$, Yiping Wei $^{1}$, De-guo Lu ${ }^{2}$, \\ Yun-wei Han ${ }^{2}$, Jianjun $\mathbf{X u}^{1}$, Dongliang $\mathbf{Y u}^{1}$ \\ ${ }^{1}$ Department of Cardiothoracic Surgery, The Second Affiliated Hospital of Nanchang University, Nanchang, Jiangxi Province \\ 330006, P. R. China \\ ${ }^{2}$ Department of Oncology, The Affiliated Hospital of Southwest Medical University, Luzhou, Sichuan 646000, China \\ *These authors have contributed equally to this work \\ Correspondence to: Dongliang Yu, email: dongliangyumd@yahoo.com \\ Jianjun XU, email: Jianjunxua@gmail.com
}

Keywords: NSCLC, notch, hazard ratio, prognosis, KM plotter

Received: August 29, 2016

Accepted: December 15, 2016

Published: January 04, 2017

\section{ABSTRACT}

Notch signalling is aberrantly activated in human non-small cell lung cancer (NSCLC). Nevertheless, the prognostic roles of mRNA expression of four Notch receptors in NSCLC patients remain elusive. In this report, we reported the prognostic roles of Notch receptors in a total of 1,926 NSCLC patients through "The KaplanMeier plotter" (KM plotter) database which is capable to assess the effect of 22,277 genes on survival of NSCLC patients. We found that mRNA high expression level of Notch1 was associated with better overall survival (OS) for all NSCLC patients, hazard ratio (HR) $0.78(0.69-0.89), p=0.00019$, better OS in adenocarcinoma (Ade) patients, HR $0.59(0.46-0.75), p=1.5 e-05$, as well as in squamous cell carcinoma (SCC) patients, HR $0.78(0.62-0.99), p=0.044$. mRNA high expression levels of Notch2 and Notch 3 were associated with worsen OS for all NSCLC patients, as well as in Ade, but not in SCC patients. mRNA high expression level of Notch4 was not found to be associated with to OS for all NSCLC patients. In addition, mRNA high expression levels of Notch2, Notch3, but Notch4 are significantly associated with the NSCLC patients who have different smoking status. Our results indicate that mRNA expression of Notch receptors may have distinct prognostic values in NSCLC patients. These results will benefit for developing tools to accurately predict the prognosis of NSCLC patients.

\section{INTRODUCTION}

Lung carcinoma is the leading cause of cancerrelated death worldwide, and among this carcinoma, non-small cell lung carcinoma (NSCLC) comprises the majority of cases [1-2]. NSCLC includes: adenocarcinoma (Ade), squamous cell carcinoma (SCC), two major histological types. In spite of the progresses in early diagnosis, radical cure treatment, and molecular targeted therapies, the majority of NSCLC patients present with advanced stage disease and recur in about one third of individuals [3-4]. Therefore, it is still needed to further investigate the molecular mechanism of initiation, development and to identify potential prognostic markers and potential drug targets of NSCLC.
The Notch signaling pathway, an evolutionarily conserved and complex signaling system is known to regulate epithelial cell and stem cell homeostasis [5-6]. Notch signalling is aberrantly activated in several human tumors including breast, colon, cervical, pancreatic, head and neck, prostate cancer, renal carcinoma, Large-cell and Hodgkin lymphomas, as well as NSCLC [7-10]. Previous reports demonstrate that Notch signaling is activated and plays a critical role in NSCLC initiation, progression, and metastasis of NSCLC [10-13]. However, the prognostic values of mRNA expression of Notch receptors in NSCLC patients have not been determined. In this report, we determined the prognostic roles of mRNA expression of four Notch receptors in NSCLC patients.

The "Kaplan-Meier plotter" (KM plotter), established using data from Gene Expression Omnibus 
database was widely used in many studies [14-22]. A number of genes, as prognostic markers or potential drug targets have been reported by using KM plotter in ovarian cancer [23-24], breast cancer [25-33], gastric cancer [21, 34], as well as in NSCLC [35]. In this report, we used KM plotter database and determined the prognostic roles of mRNA expression of Notch receptors in NSCLC patients.

\section{RESULTS}

It is well known that Notch signaling have four receptors, Notch1 4. All Notch receptors can be found in the database (www.kmplot.com).

We used KM plotter and determined theprognostic value of Notch1 in the database. The Affymetrix IDs is valid: 218902 at (Notch1). Survival curves are drafted for all NSCLC patients $(n=1,926)$ (Figure 1A), for Ade patients $(\mathrm{n}=720)$ (Figure $1 \mathrm{~B})$, and for SCC patients (n =524) (Figure 1C). Notch1 mRNA high expression was correlated to better overall survival (OS) for all NSCLC patients who were followed for 20 years, hazard ratio (HR) 0.78 (0.69-0.89), $p=0.00019$. Notch1 mRNA high expression was also correlated to better OS in Ade patients, HR $0.59(0.46-0.75), p=1.5 \mathrm{e}-05$, as well as in SCC patients, HR 0.78 (0.62-0.99), $p=0.044$.

We next determined the prognostic value of Notch2 in the database. The Affymetrix IDs is valid: 210756_s_at (Notch2). Notch 2 mRNA high expression was significantly correlated to worsen OS for all patients, HR 1.29 (1.131.46), $p=9.1 \mathrm{e}-05$ (Figure 2A). Notch2 mRNA high expression was also correlated to worsen OS in Ade patients, HR 2.2 (1.72-2.81), $p=9.2 \mathrm{e}-11$ (Figure 2B), but not in SCC patients, HR 1 (0.79-1.26), $p=0.99$ (Figure 2C).
Figure 3 demonstrates the prognostic value of Notch 3 in the database. The Affymetrix IDs is valid: 203237_at (Notch3). Notch3 mRNA high expression was significantly correlated to worsen OS for all patients, HR 1.19 (1.05-1.36), $p=0.006$ (Figure 3A) and Ade patients, HR 1.82 (1.44-2.3), $p=4 \mathrm{e}-07$ (Figure 3B), but not SCC patients, HR 0.95 (0.75-1.2), $p=0.66$ (Figure 3C).

Figure 4 demonstrates the prognostic value of Notch4 in the database. The Affymetrix IDs is valid: 205247_at (Notch4). Notch4 mRNA high expression was not significantly correlated to OS for all NSCLC patients, HR1.02 (0.9-1.16), $p=0.72$ (Figure 4A), Ade patients, HR 1.16 (0.92-1.47), $p=0.2$ (Figure 4B), as well as patients with SCC, HR 0.92 (0.72-1.17), $p=0.49$ (Figure 4C).

For further assess the association of Notch receptors with other clinicopathological profiles, we determined the correlation with the patients' smoking status (Table 1), clinical different stages (Table 2) and different chemotherapeutic treatment (Table 3). As from Table 1, Notch2, Notch3, but Notch4 are significantly correlated with the smoking status. Notch 1 only significantly associated with smoked NSCLC patients. From Table 2, Notch1 and Notch2 are significantly correlated with clinical stage I \& II of the patients. Notch 3 is only significantly associated with clinical stage I of NSCLC patients. From Table 3, only Notch3 is significantly correlated with the patients without chemotherapy.

\section{DISCUSSION}

KM plotter was initially formed to access the prognostic value of an individual gene using online database in breast cancer patients [36-37]. A number
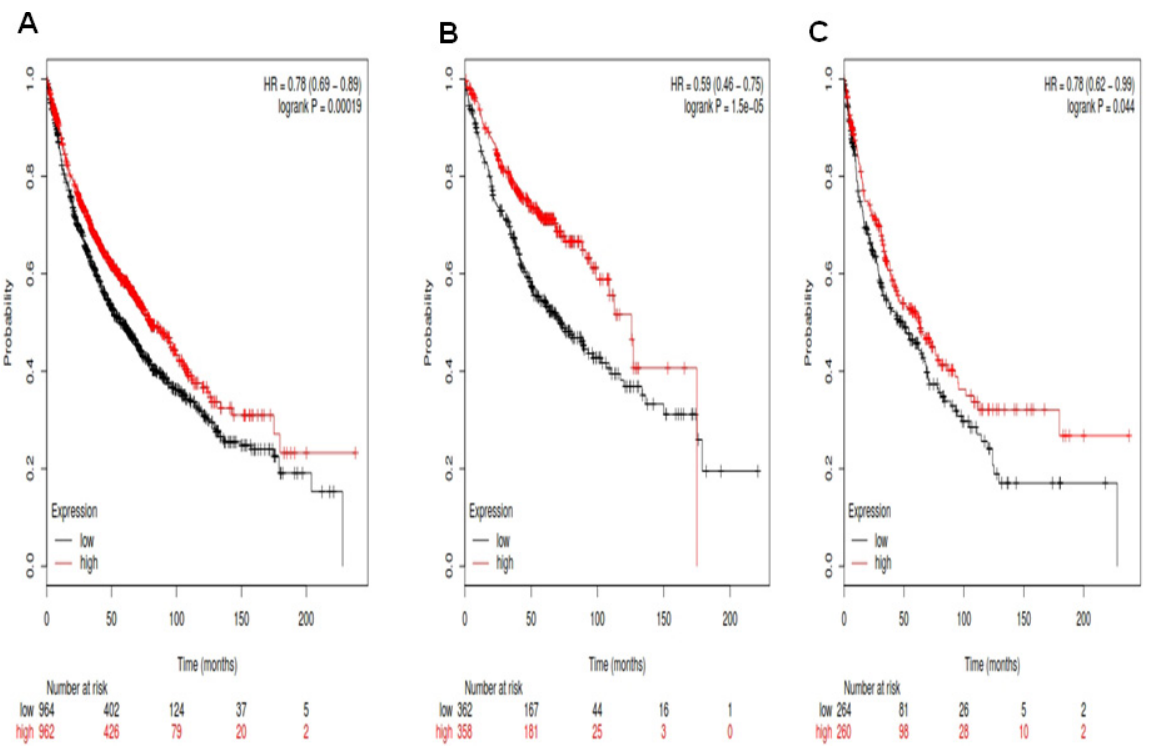

Figure 1: Determination of prognostic value of Notch1 mRNA expression in the database. The Affymetrix IDs is valid: 218902_at (Notch1). A. Survival curves are plotted for all NSCLC patients $(\mathrm{n}=1,926)$. B. Survival curves are plotted for adenocarcinoma $(\mathrm{n}=720)$. C. Survival curves are plotted for squamous cell carcinoma $(\mathrm{n}=524)$. 
A

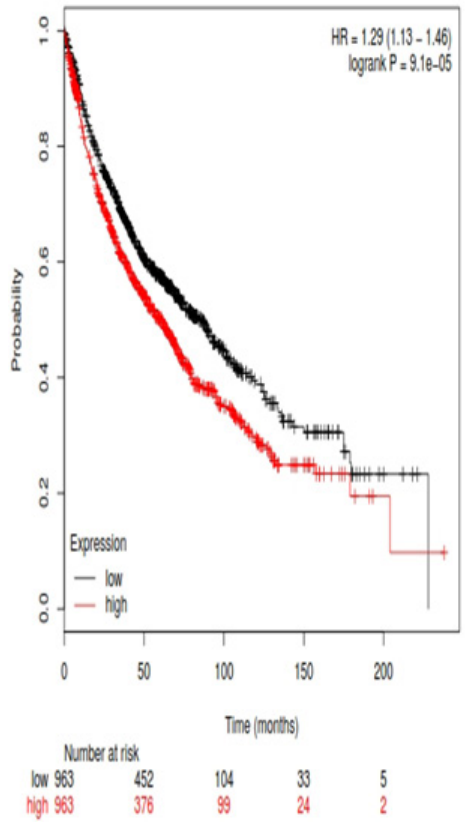

B

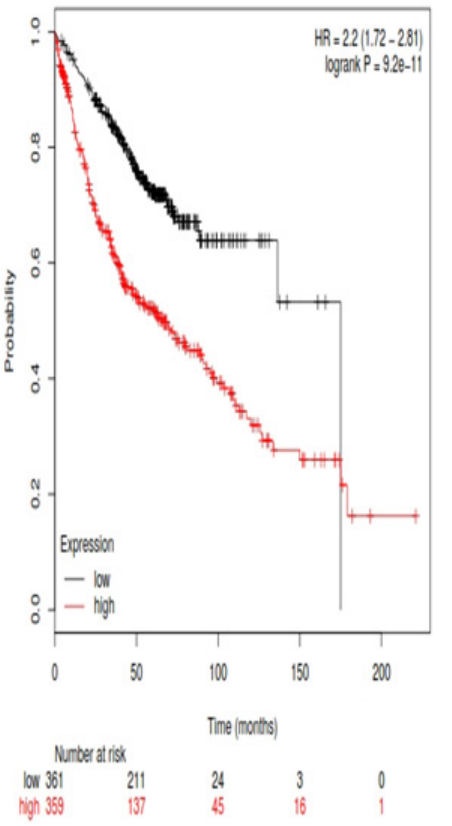

C

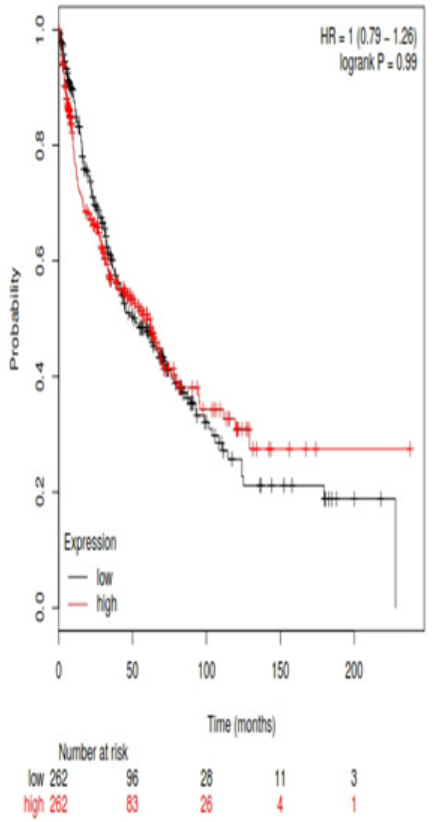

Figure 2: Determination of prognostic value of Notch 2 mRNA expression in the database. The Affymetrix IDs is valid: 210756 s at (Notch2). A. Survival curves are plotted for all NSCLC patients $(n=1,926)$. B. Survival curves are plotted for adenocarcinoma $(\mathrm{n}=720)$. C. Survival curves are plotted for squamous cell carcinoma $(\mathrm{n}=524)$.

A

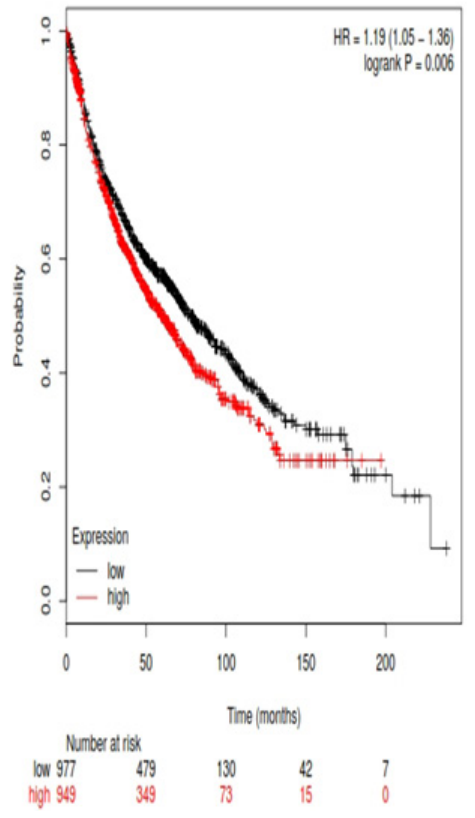

B

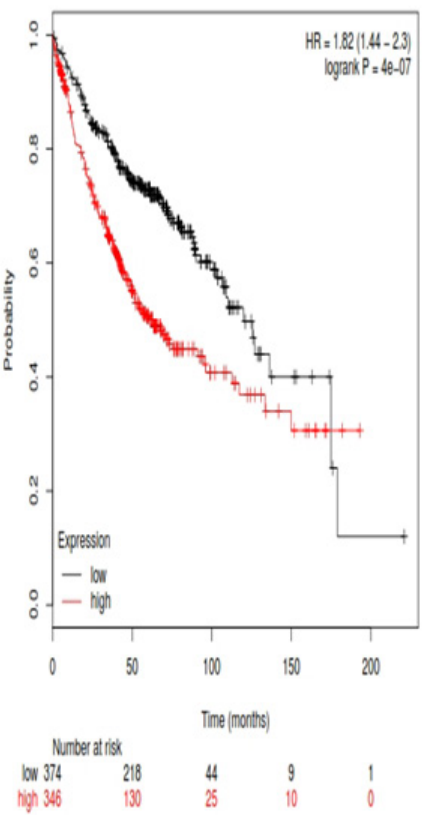

C

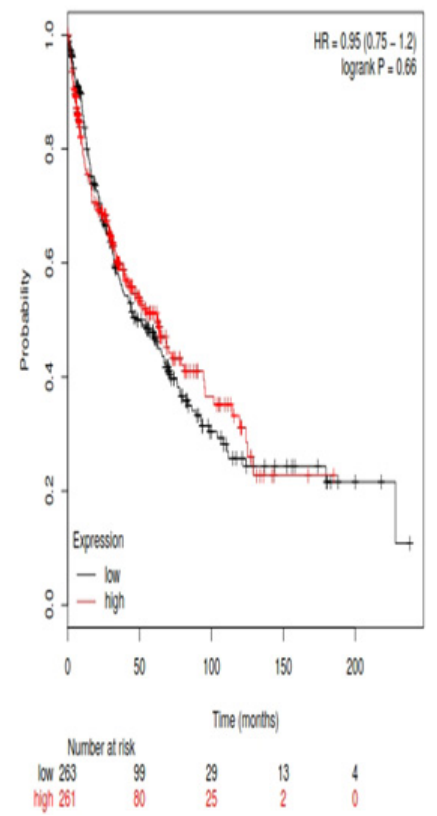

Figure 3: Determination of prognostic value of Notch3 mRNA expression in the database. The Affymetrix IDs is valid: 203237_at (Notch3). A. Survival curves are plotted for all NSCLC patients $(\mathrm{n}=1,926)$. B. Survival curves are plotted for adenocarcinoma $(\mathrm{n}=720)$. C. Survival curves are plotted for squamous cell carcinoma $(\mathrm{n}=524)$. 
of genes, such as ABCC2, BUBR1, CCND2, CCND3, CCNDE2, GREB1, MKI67, TK2, CDKN1A, TOP2A and TOP2B used this tool to validate or confirm the prognostic power in breast cancer [25-31, 38] and/or lung cancer [35]. In addition, several proteins were identified by KM plotter as potential drug targets, such as S100P [29], carbonic anhydrase IX (CAIX) [32], Notch1 [39] in breast cancer, aldehyde dehydrogenase 1 (ALDH1) [40] in NSCLC, Notch2 [24] in ovarian cancer.

Notch1, among four Notch receptors, is the best studied in NSCLC carcinogenesis [41-44]. Increased frequency of Notch1 activation can induce lung adenoma formation and enable progression to Ade and metastases [45]. Notch1 activation can also enhance epithelialmesenchymal transition (EMT) in lung cancer cells [4647]. Cisplatin was also observed to activate Notch1 first, then further induce the enrichment of CD133 positive cells in lung Ade [48]. Notch1 function was found to be required for tumor initiation through suppression of $\mathrm{p} 53$ mediated apoptosis in NSCLC [49]. But recently, Wael et al observed that Notch1 expression has a tumor inhibitory effect on Ade cells, but not SCC cells in NSCLC [50]. A meta-analysis showed that Notch1 was correlated with lymph node metastasis, TNM stages and significantly poor OS in NSCLC patients [51]. Notch1 mRNA was expressed on both mesenchymal and epithelial structures of the embryonic lung, indicating that Notch1 has a role in the vascular morphogenesis and lung development [52]. In our report, mRNA high expression of Notch1 was correlated to better OS for all NSCLC patients, also better OS in Ade and SCC patients.

Notch2 is a tumor suppressor in lung carcinogenesis [53]. But, the prognostic significance of either Notch2 protein or mRNA in NSCLC patients is not known. In our report, mRNA high expression of Notch2 was significantly correlated to worsen OS for all NSCLC patients, HR 1.29 (1.13-1.46), $p=9.1 \mathrm{e}-05$. Notch 2 mRNA high expression was also correlated to worsen OS in Ade patients, HR $2.2(1.72-2.81), p=9.2 \mathrm{e}-11$, but not in SCC patients, HR 1 $(0.79-1.26), p=0.99$.

Notch3 potentially contributes to the multistep evolution of lung cancer in airway epithelium by using a transgenic mouse model [54]. High Notch3 expression may contribute the resistance to chemotherapy in lung cancer patients [55]. Notch3 was found to upregulate ZEB-1, which leads to TGF- $\beta$-induced the EMT and bone metastasis in NSCLC [56]. A report showed that Notch3 was an independent prognostic factor for patients with NSCLC [57]. In consistent with previous report, our results showed that mRNA high expression of Notch3 was found to be significantly correlated to worsen OS for all NSCLC patients, HR 1.19 (1.05-1.36), $p=0.006$ and Ade patients, HR 1.82 (1.44-2.3), $p=4 \mathrm{e}-07$, but not patients with SCC, HR $0.95(0.75-1.2), p=0.66$.

Notch4 is an oncogene in mammary tumor [5859]. Notch4 was able to expended the tumorigenicity in mammary epithelial cells [60-61]. Although Notch4 was detected in both tumor and stromal compartments
A

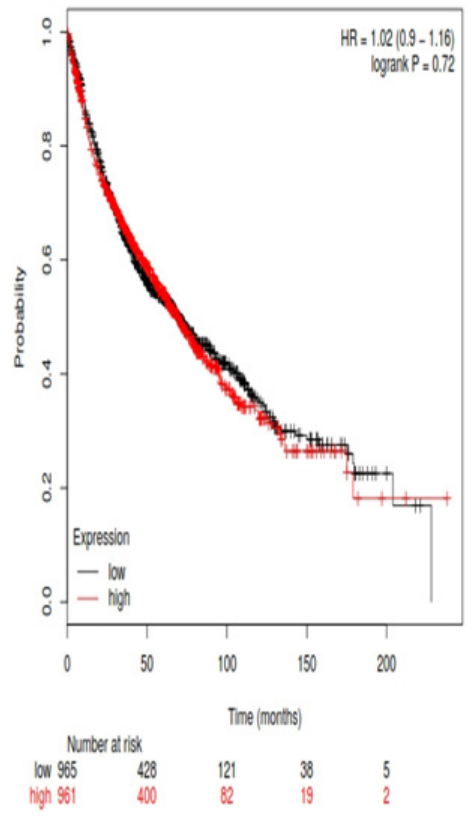

B

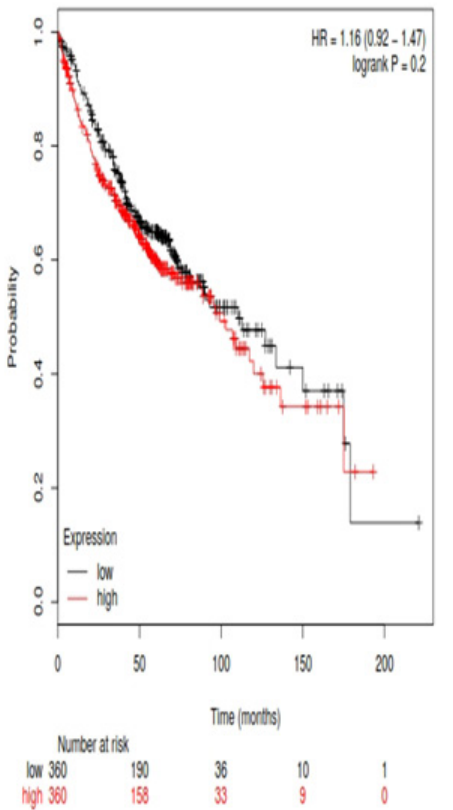

C

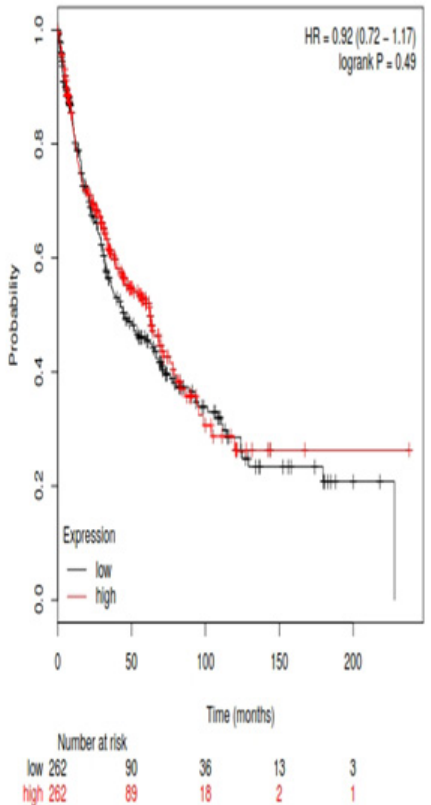

Figure 4: Determination of prognostic value of Notch3 mRNA expression in the database. The Affymetrix IDs is valid: 205247_at (Notch4). A. Survival curves are plotted for all NSCLC patients $(\mathrm{n}=1,926)$. B. Survival curves are plotted for adenocarcinoma $(\mathrm{n}=720)$. C. Survival curves are plotted for squamous cell carcinoma $(\mathrm{n}=524)$. 
Table 1: Correlation of Notch receptor mRNA expression with smoking status of NSCLC patients

\begin{tabular}{lccccc}
\hline Notch receptors & Smoking status & Cases & HR & 95\% CI & P value \\
\hline Notch1 & Never smoked & 205 & 0.6 & $(0.34-1.06)$ & 0.067 \\
& Smoked & 820 & 0.71 & $(0.58-0.88)$ & 0.0016 \\
\multirow{2}{*}{ Notch2 } & Never smoked & 205 & 2.97 & $(1.6-5.52)$ & 0.00031 \\
& Smoked & 820 & 1.43 & $(1.16-1.76)$ & 0.00091 \\
Notch3 & Never smoked & 205 & 2.85 & $(1.57-5.17)$ & 0.00032 \\
& Smoked & 820 & 1.41 & $(1.15-1.74)$ & 0.001 \\
Notch4 & Never smoked & 205 & 1.03 & $(0.59-1.8)$ & 0.9 \\
& Smoked & 820 & 1.22 & $(0.99-1.49)$ & 0.064 \\
\hline
\end{tabular}

Table 2: Correlation of Notch receptor mRNA expression with clinical stages of NSCLC patients

\begin{tabular}{lccccc}
\hline Notch receptors & Clinical stages & Cases & HR & $\mathbf{9 5 \%}$ CI & P value \\
\hline Notch 1 & I & 577 & 0.54 & $(0.41-0.71)$ & $1 \mathrm{e}-05$ \\
& II & 244 & 0.52 & $(0.35-0.75)$ & 0.00042 \\
Notch 2 & III & 70 & 1.04 & $(0.6-1.79)$ & 0.89 \\
& I & 577 & 2.09 & $(1.58-2.77)$ & $1.3 \mathrm{e}-07$ \\
& II & 244 & 1.77 & $(1.22-2.56)$ & 0.0022 \\
Notch 3 & III & 0.86 & $(0.5-1.49)$ & 0.6 \\
& I & 577 & 1.8 & $(1.37-2.36)$ & $1.9 \mathrm{e}-05$ \\
& II & 244 & 1.41 & $(0.98-2.04)$ & 0.063 \\
Notch 4 & III & 70 & 0.93 & $(0.54-1.6)$ & 0.8 \\
& I & 577 & 0.93 & $(0.71-1.21)$ & 0.57 \\
& II & 244 & 0.91 & $(0.63-1.31)$ & 0.61 \\
& III & 70 & 0.77 & $(0.45-1.32)$ & 0.34 \\
\hline
\end{tabular}

Table 3: Correlation of Notch receptor mRNA expression with chemotherapy of NSCLC patients

\begin{tabular}{lccccc}
\hline Notch receptors & Chemotherapy & Cases & HR & $\mathbf{9 5 \% ~ C I ~}$ & P value \\
\hline \multirow{2}{*}{ Notch1 } & No & 310 & 1.08 & $(0.77-1.51)$ & 0.66 \\
& Yes & 176 & 0.76 & $(0.5-1.16)$ & 0.21 \\
\multirow{2}{*}{ Notch2 } & No & 310 & 1.11 & $(0.8-1.56)$ & 0.53 \\
& Yes & 176 & 0.75 & $(0.49-1.16)$ & 0.19 \\
\multirow{2}{*}{ Notch3 } & No & 310 & 1.4 & $(1-1.97)$ & 0.048 \\
& Yes & 176 & 0.76 & $(0.51-1.15)$ & 0.19 \\
\multirow{2}{*}{ Notch4 } & No & 310 & 1.18 & $(0.85-1.66)$ & 0.32 \\
& Yes & 176 & 0.8 & $(0.54-1.2)$ & 0.29 \\
\hline
\end{tabular}


of NSCLC [62], the significance of Notch4 in NSCLC needs to be further determined. In this report, mRNA high expression of Notch4 was not significantly correlated to OS for all NSCLC patients, Ade patients, as well as SCC patients.

Nicotine can deregulate essential biological activities such as the cell apoptosis, proliferation, migration, invasion, inflammation, cell-mediated immunity and angiogenesis [63]. Nicotine might be promoting NSCLC growth and metastasis by inducing the secretion of stem cell factor [64]. There is no report regarding whether there is a direct correlation between nicotine and Notch activation in NSCLC. However, Hirata et al [65] reported that nicotine can increase ALDH-positive cells through a PKC-Notch pathway in MCF-7 cells. In addition, nicotine may impact specific Notch members in endothelial cells [66] or dendritic cells [67], thus indirectly impact NSCLC. Nicotine was also reported recently to enhance the expression of synaptic and Notch1 proteins in stressed animals [68]. In this report, we observed that high mRNA expression of Notch2, Notch3, but Notch4 are correlated with smoking status of NSCLC patients. High mRNA expression of Notch 1 is only significantly associated with smoked NSCLC patients.

Previous results suggest that Notch signaling, especially Notch receptors may be essential drug target for NSCLC patients. $\gamma$-secretase inhibitor, DAPT was demonstrated to inhibit Notch activation and cell growth in NSCLC cells [69]. However, $\gamma$-secretase inhibitors are not able to distinguish individual Notch receptors and may cause intestinal toxicity [70] by inhibiting other signaling pathways [71]. Recently, phage display technology may produce highly specialized antibodies which can recognize each Notch receptor paralogue in human patients and rodent models [72]. Based on our study that mRNA high expression of Notch 2 and Notch 3 was correlated to worsen OS for all NSCLC patients, thus Notch2 and Notch3 might be potential drug targets for NSCLC patients.

In summary, we demonstrated that Notch1 mRNA high expression was correlated to better OS for all NSCLC patients. Notch 2 and Notch 3 mRNA high expression were correlated to worsen OS for all NSCLC patients. Notch 4 mRNA high expression were not correlated to OS for all NSCLC patients. These results will be useful for better understand the complexity and heterogeneity in the molecular biology of NSCLC and to develop tools to more accurately predict their prognosis. Based on our study, Notch 2 and Notch3 might be potential drug targets for NSCLC patients.

\section{MATERIALS AND METHODS}

An online database [36] was used to determine the relevance and significance of Notch receptors' mRNA expression to overall survival (OS). NSCLC patients in the KM plotter database were come from the Gene Expression Omnibus (GEO, http://www.ncbi. nlm.nih.gov/geo/), Cancer Biomedical Informatics Grid (caBIG, https://biospecimens.cancer.gov/ relatedinitiatives/overview/caBig.asp), and The Cancer Genome Atlas (TCGA, http://cancergenome.nih.gov) lung cancer datasets [73]. The database was established using gene expression data and survival information of 1,928 NSCLC patients downloaded from above three datasets. The NSCLC patients were followed up 20 years. By using KM plotter, four Notch receptors (Notch1, Notch2, Notch3 and Notch4) were entered into the database (http://kmplot.com/analysis/index. $\mathrm{php} ? \mathrm{p}=$ service \&cancer=breast) to obtain Kaplan-Meier survival plots in which the number-at-risk is indicated below the main plot. The certain gene mRNA expression above or below the median separates the cases into high expression and low expression. Hazard ratio (and 95\% confidence intervals) and log rank $\mathrm{P}$ were calculated and displayed on the webpage.

\section{CONFLICTS OF INTEREST}

The authors have no financial interest in this project.

\section{Author contributions}

JX, XZ, DY participated in the design of the study and drafted the manuscript. JX, XZ, XC, YW, DL, YH, JJX reviewed and extracted data. JX, XZ and DY participated in the search the study and performed the statistical analysis. JX and DY wrote the manuscript. All authors reviewed the manuscript.

\section{REFERENCES}

1. Siegel R, Naishadham D, Jemal A. Cancer statistics, 2012. CA Cancer J Clin. 2012; 62:10-29.

2. Guo P, Huang ZL, Yu P, Li K. Trends in cancer mortality in China: an update. Ann Oncol. 2012; 23:2755-2762.

3. Ramalingam S, Belani C. Systemic chemotherapy for advanced non-small cell lung cancer: recent advances and future directions. Oncologist. 2008; 13:5-13.

4. DeSantis CE, Lin CC, Mariotto AB, Siegel RL, Stein KD, Kramer JL, Alteri R, Robbins AS, Jemal A. Cancer treatment and survivorship statistics, 2014. CA Cancer J Clin. 2014; 64:252-271.

5. Lewis J. Notch signalling and the control of cell fate choices in vertebrates. Semin Cell Dev Biol. 1998; 9:583-589.

6. Simpson P. Developmental genetics. The Notch connection. Nature. 1995; 375:736-737.

7. Kopan R, Ilagan MX. The canonical Notch signaling pathway: unfolding the activation mechanism. Cell. 2009; 137:216-233.

8. Miele L. Notch signaling. Clin Cancer Res. 2006; 12:1074-1079. 
9. Miele L, Miao H, Nickoloff BJ. NOTCH signaling as a novel cancer therapeutic target. Curr Cancer Drug Targets. 2006; 6:313-323.

10. Alketbi A, Attoub S. Notch Signaling in Cancer: Rationale and Strategies for Targeting. Curr Cancer Drug Targets. 2015; 15:364-374.

11. O'Flaherty JD, Barr M, Fennell D, Richard D, Reynolds J, O'Leary J, O'Byrne K. The cancer stem-cell hypothesis: its emerging role in lung cancer biology and its relevance for future therapy. J Thorac Oncol. 2012; 7:1880-1890.

12. Nguyen D, Rubinstein L, Takebe N, Miele L, Tomaszewski JE, Ivy P, Doroshow JH, Yang SX. Notch1 phenotype and clinical stage progression in non-small cell lung cancer. J Hematol Oncol. 2015; 8:9.

13. Westhoff B, Colaluca IN, D'Ario G, Donzelli M, Tosoni D, Volorio S, Pelosi G, Spaggiari L, Mazzarol G, Viale G, Pece S, Di FPP. Alterations of the Notch pathway in lung cancer. Proc Natl Acad Sci U S A. 2009; 106:22293-22298.

14. Zhu J, Ma J, Wang X, Ma T, Zhang S, Wang W, Zhou X, Shi J. High Expression of PHGDH Predicts Poor Prognosis in Non-Small Cell Lung Cancer. Transl Oncol. 2016; 9:592-599.

15. Cai XP, Chen LD, Song HB, Zhang CX, Yuan ZW, Xiang ZX. PLK1 promotes epithelial-mesenchymal transition and metastasis of gastric carcinoma cells. Am J Transl Res. 2016; 8:4172-4183.

16. Li K, Ying M, Feng D, Du J, Chen S, Dan B, Wang C, Wang Y. Fructose-1,6-bisphosphatase is a novel regulator of Wnt/beta-Catenin pathway in breast cancer. Biomed Pharmacother. 2016; 84:1144-1149.

17. Xu Z, Zhou Y, Cao Y, Dinh TL, Wan J, Zhao M. Identification of candidate biomarkers and analysis of prognostic values in ovarian cancer by integrated bioinformatics analysis. Med Oncol. 2016; 33:130.

18. Gao Z, Shi R, Yuan K, Wang Y. Expression and prognostic value of E2F activators in NSCLC and subtypes: a research based on bioinformatics analysis. Tumour Biol. 2016; 37:14979-14987.

19. Kong PZ, Li GM, Tian Y, Song B, Shi R. Decreased expression of FOXF2 as new predictor of poor prognosis in stage I non-small cell lung cancer. Oncotarget. 2016; 28:10876. doi: 10.18632/oncotarget.10876.

20. Wu X, Liu W, Tang D, Xiao H, Wu Z, Chen C, Yao X, Liu F, Li G. Prognostic values of four Notch receptor mRNA expression in gastric cancer. Sci Rep. 2016; 6:28044.

21. Xia $\mathrm{P}, \mathrm{Xu} \mathrm{XY}$. Prognostic significance of CD44 in human colon cancer and gastric cancer: evidence from bioinformatic analyses. Oncotarget. 2016; 7:45538-45546. doi: 10.18632/oncotarget.9998.

22. Li Z, Yamada S, Wu Y, Wang KY, Liu YP, Uramoto H, Kohno K, Sasaguri Y. Polypeptide N-acetylgalactosaminylt ransferase- 6 expression independently predicts poor overall survival in patients with lung adenocarcinoma after curative resection. Oncotarget. 2016; 7:54463-54473. doi: 10.18632/ oncotarget.9810.

23. Ocana A, Perez-Pena J, Alcaraz-Sanabria A, SanchezCorrales V, Nieto-Jimenez C, Templeton AJ, Seruga B, Pandiella A, Amir E. In silico analyses identify gene-sets, associated with clinical outcome in ovarian cancer: role of mitotic kinases. Oncotarget. 2016; 7:22865-22872. doi: 10.18632/oncotarget.8118.

24. Zhou X, Teng L, Wang M. Distinct prognostic values of four-Notch-receptor mRNA expression in ovarian cancer. Tumour Biol. 2016; 37:6979-6985.

25. Liu M, Wang G, Gomez-Fernandez CR, Guo S. GREB1 Functions as a Growth Promoter and Is Modulated by IL6/ STAT3 in Breast Cancer. Plos one. 2012; 7:e46410.

26. Tilghman SL, Townley I, Zhong Q, Carriere PP, Zou J, Llopis SD, Preyan LC, Williams CC, Skripnikova E, Bratton MR, Zhang Q, Wang G. Proteomic signatures of acquired letrozole resistance in breast cancer: suppressed estrogen signaling and increased cell motility and invasiveness. Mol Cell Proteomics. 2013; 12:2440-2455.

27. Zhou C, Zhong Q, Rhodes LV, Townley I, Bratton MR, Zhang Q, Martin EC, Elliott S, Collins-Burow BM, Burow $\mathrm{ME}$, Wang G. Proteomic analysis of acquired tamoxifen resistance in MCF-7 cells reveals expression signatures associated with enhanced migration. Breast Cancer Res. 2012; 14:R45.

28. Maciejczyk A, Szelachowska J, Czapiga B, Matkowski R, Halon A, Gyorffy B, Surowiak P. Elevated BUBR1 expression is associated with poor survival in early breast cancer patients: 15-year follow-up analysis. J Histochem Cytochem. 2013; 61:330-339.

29. Maciejczyk A, Lacko A, Ekiert M, Jagoda E, Wysocka T, Matkowski R, Halon A, Gyorffy B, Lage H, Surowiak P. Elevated nuclear S100P expression is associated with poor survival in early breast cancer patients. Histol Histopathol. 2013; 28:513-524.

30. Maciejczyk A, Jagoda E, Wysocka T, Matkowski R, Gyorffy B, Lage H, Surowiak P. ABCC2 (MRP2, cMOAT) localized in the nuclear envelope of breast carcinoma cells correlates with poor clinical outcome. Pathol Oncol Res. 2012; 18:331-342.

31. Adam MA. New prognostic factors in breast cancer. Adv Clin Exp Med. 2013; 22:5-15.

32. Ivanova L, Zandberga E, Silina K, Kalnina Z, Abols A, Endzelins E, Vendina I, Romanchikova N, Hegmane A, Trapencieris P, Eglitis J, Line A. Prognostic relevance of carbonic anhydrase IX expression is distinct in various subtypes of breast cancer and its silencing suppresses selfrenewal capacity of breast cancer cells. Cancer Chemother Pharmacol. 2015; 75:235-246.

33. Wu S, Xue W, Huang X, Yu X, Luo M, Huang Y, Liu Y, Bi Z, Qiu X, Bai S. Distinct prognostic values of ALDH1 isoenzymes in breast cancer. Tumour Biol. 2015; 13:13. 
34. Shen JX, Liu J, Li GW, Huang YT, Wu HT. Mining distinct aldehyde dehydrogenase 1 (ALDH1) isoenzymes in gastric cancer. Oncotarget. 2016; 7:25340-25349. doi: 10.18632/ oncotarget.8294.

35. Ortega CE, Seidner Y, Dominguez I. Mining CK2 in cancer. Plos one. 2014; 9:e115609.

36. Gyorffy B, Lanczky A, Eklund AC, Denkert C, Budczies J, Li Q, Szallasi Z. An online survival analysis tool to rapidly assess the effect of 22,277 genes on breast cancer prognosis using microarray data of 1,809 patients. Breast Cancer Res Treat. 2010; 123:725-731.

37. Gyorffy B, Benke Z, Lanczky A, Balazs B, Szallasi Z, Timar J, Schafer R. RecurrenceOnline: an online analysis tool to determine breast cancer recurrence and hormone receptor status using microarray data. Breast Cancer Res Treat. 2012; 132:1025-1034.

38. Xu J, Song F, Jin T, Qin J, Wu J, Wang M, Wang Y, Liu J. Prognostic values of Notch receptors in breast cancer. Tumour Biol. 2015; 1:1.

39. Xu J, Song F, Jin T, Qin J, Wu J, Wang M, Wang Y, Liu J. Prognostic values of Notch receptors in breast cancer. Tumour Biol. 2016; 37:1871-1877.

40. You Q, Guo H, Xu D. Distinct prognostic values and potential drug targets of ALDH1 isoenzymes in non-smallcell lung cancer. Drug Des Devel Ther. 2015; 9:5087-5097.

41. Yuan X, Wu H, Han N, Xu H, Chu Q, Yu S, Chen Y, Wu $\mathrm{K}$. Notch signaling and EMT in non-small cell lung cancer: biological significance and therapeutic application. J Hematol Oncol. 2014; 7:87.

42. Xu K, Moghal N, Egan SE. Notch signaling in lung development and disease. Adv Exp Med Biol. 2012; 727:89-98.

43. Galluzzo P, Bocchetta M. Notch signaling in lung cancer. Expert Rev Anticancer Ther. 2011; 11:533-540.

44. Collins BJ, Kleeberger W, Ball DW. Notch in lung development and lung cancer. Semin Cancer Biol. 2004; $14: 357-364$

45. Allen TD, Rodriguez EM, Jones KD, Bishop JM. Activated Notch1 induces lung adenomas in mice and cooperates with Myc in the generation of lung adenocarcinoma. Cancer Res. 2011; 71:6010-6018.

46. Xie M, Zhang L, He CS, Xu F, Liu JL, Hu ZH, Zhao LP, Tian Y. Activation of Notch-1 enhances epithelialmesenchymal transition in gefitinib-acquired resistant lung cancer cells. J Cell Biochem. 2012; 113:1501-1513.

47. Xie M, He CS, Wei SH, Zhang L. Notch-1 contributes to epidermal growth factor receptor tyrosine kinase inhibitor acquired resistance in non-small cell lung cancer in vitro and in vivo. Eur J Cancer. 2013; 49:3559-3572.

48. Liu YP, Yang CJ, Huang MS, Yeh CT, Wu AT, Lee YC, Lai TC, Lee CH, Hsiao YW, Lu J, Shen CN, Lu PJ, Hsiao M. Cisplatin selects for multidrug-resistant CD133+ cells in lung adenocarcinoma by activating Notch signaling. Cancer Res. 2013; 73:406-416.
49. Licciulli S, Avila JL, Hanlon L, Troutman S, Cesaroni M, Kota S, Keith B, Simon MC, Pure E, Radtke F, Capobianco AJ, Kissil JL. Notch1 is required for Kras-induced lung adenocarcinoma and controls tumor cell survival via p53. Cancer Res. 2013; 73:5974-5984.

50. Wael H, Yoshida R, Kudoh S, Hasegawa K, Niimori-Kita K, Ito T. Notch1 signaling controls cell proliferation, apoptosis and differentiation in lung carcinoma. Lung Cancer. 2014; 85:131-140.

51. Yuan X, Wu H, Xu H, Han N, Chu Q, Yu S, Chen Y, Wu $\mathrm{K}$. Meta-analysis reveals the correlation of Notch signaling with non-small cell lung cancer progression and prognosis. Sci Rep. 2015; 5:10338.

52. Taichman DB, Loomes KM, Schachtner SK, Guttentag $\mathrm{S}$, Vu C, Williams P, Oakey RJ, Baldwin HS. Notch1 and Jagged1 expression by the developing pulmonary vasculature. Dev Dyn. 2002; 225:166-175.

53. Baumgart A, Mazur PK, Anton M, Rudelius M, Schwamborn K, Feuchtinger A, Behnke K, Walch A, Braren R, Peschel C, Duyster J, Siveke JT, Dechow T. Opposing role of Notch1 and Notch2 in a Kras(G12D)-driven murine non-small cell lung cancer model. Oncogene. 2015; 34:578-588.

54. Dang TP, Eichenberger S, Gonzalez A, Olson S, Carbone DP. Constitutive activation of Notch3 inhibits terminal epithelial differentiation in lungs of transgenic mice. Oncogene. 2003; 22:1988-1997.

55. Shi C, Qian J, Ma M, Zhang Y, Han B. Notch 3 protein, not its gene polymorphism, is associated with the chemotherapy response and prognosis of advanced NSCLC patients. Cell Physiol Biochem. 2014; 34:743-752.

56. Liu L, Chen X, Wang Y, Qu Z, Lu Q, Zhao J, Yan X, Zhang $\mathrm{H}$, Zhou Y. Notch3 is important for TGF-beta-induced epithelial-mesenchymal transition in non-small cell lung cancer bone metastasis by regulating ZEB-1. Cancer Gene Ther. 2014; 21:364-372.

57. Ye YZ, Zhang ZH, Fan XY, Xu XL, Chen ML, Chang BW, Zhang YB. Notch3 overexpression associates with poor prognosis in human non-small-cell lung cancer. Med Oncol. $2013 ; 30: 595$.

58. Gallahan D, Jhappan C, Robinson G, Hennighausen L, Sharp R, Kordon E, Callahan R, Merlino G, Smith GH. Expression of a truncated Int3 gene in developing secretory mammary epithelium specifically retards lobular differentiation resulting in tumorigenesis. Cancer Res. 1996; 56:1775-1785.

59. Jhappan C, Gallahan D, Stahle C, Chu E, Smith GH, Merlino G, Callahan R. Expression of an activated Notchrelated int-3 transgene interferes with cell differentiation and induces neoplastic transformation in mammary and salivary glands. Genes Dev. 1992; 6:345-355.

60. Soriano JV, Uyttendaele H, Kitajewski J, Montesano R. Expression of an activated Notch4(int-3) oncoprotein disrupts morphogenesis and induces an invasive phenotype 
in mammary epithelial cells in vitro. Int J Cancer. 2000; 86:652-659.

61. Callahan R, Raafat A. Notch signaling in mammary gland tumorigenesis. J Mammary Gland Biol Neoplasia. 2001; 6:23-36.

62. Andersen S, Donnem T, Al-Saad S, Al-Shibli K, Stenvold $\mathrm{H}$, Busund LT, Bremnes RM. Correlation and coexpression of HIFs and NOTCH markers in NSCLC. Anticancer Res. 2011; 31:1603-1606.

63. Cardinale A, Nastrucci C, Cesario A, Russo P. Nicotine: specific role in angiogenesis, proliferation and apoptosis. Crit Rev Toxicol. 2012; 42:68-89.

64. Perumal D, Pillai S, Nguyen J, Schaal C, Coppola D, Chellappan SP. Nicotinic acetylcholine receptors induce c-Kit ligand/Stem Cell Factor and promote stemness in an ARRB1/ beta-arrestin-1 dependent manner in NSCLC. Oncotarget. 2014; 5:10486-10502. doi: 10.18632/oncotarget.2395.

65. Hirata N, Sekino Y, Kanda Y. Nicotine increases cancer stem cell population in MCF-7 cells. Biochem Biophys Res Commun. 2010; 403:138-143.

66. Manda VK, Mittapalli RK, Geldenhuys WJ, Lockman PR. Chronic exposure to nicotine and saquinavir decreases endothelial Notch-4 expression and disrupts blood-brain barrier integrity. J Neurochem. 2010; 115:515-525.

67. Nouri-Shirazi M, Kahlden C, Nishino P, Guinet E. Nicotine exposure alters the mRNA expression of Notch ligands in dendritic cells and their response to Th1-/Th2-promoting stimuli. Scand J Immunol. 2015; 81:110-120.

68. Shang X, Shang Y, Fu J, Zhang T. Nicotine Significantly Improves Chronic Stress-Induced Impairments of Cognition and Synaptic Plasticity in Mice. Mol Neurobiol. 2016; $12: 12$.

69. Liu J, Mao Z, Huang J, Xie S, Liu T. Blocking the NOTCH pathway can inhibit the growth of CD133-positive A549 cells and sensitize to chemotherapy. Biochem Biophys Res Commun. 2014; 444:670-675.

70. van Es JH, van Gijn ME, Riccio O, van den Born M, Vooijs M, Begthel H, Cozijnsen M, Robine S, Winton DJ, Radtke F, Clevers H. Notch/gamma-secretase inhibition turns proliferative cells in intestinal crypts and adenomas into goblet cells. Nature. 2005; 435:959-963.

71. Beel AJ, Sanders CR. Substrate specificity of gammasecretase and other intramembrane proteases. Cell Mol Life Sci. 2008; 65:1311-1334.

72. Wu Y, Cain-Hom C, Choy L, Hagenbeek TJ, de Leon GP, Chen Y, Finkle D, Venook R, Wu X, Ridgway J, SchahinReed D, Dow GJ, Shelton A, et al. Therapeutic antibody targeting of individual Notch receptors. Nature. 2010; 464:1052-1057.

73. Gyorffy B, Surowiak P, Budczies J, Lanczky A. Online survival analysis software to assess the prognostic value of biomarkers using transcriptomic data in non-small-cell lung cancer. Plos one. 2013; 8:e82241. 